\title{
Spontaneous puberty in Turner's syndrome: A case report
}

\author{
Sarah Ramamurthy ${ }^{1}$, Aravindhan Karuppusamy ${ }^{2, *}$, Latha Chaturvedula ${ }^{3}$ \\ ${ }^{1}$ Assistant Professor, ${ }^{2}$ Additional Professor, Dept. of Anatomy, ${ }^{3}$ Professor, Dept. of Obstetrics \& Gynaeclogy, \\ ${ }^{1}$ Pondicherry Institute of Medical Sciences, Pondicherry, ${ }^{2,3}$ Jawaharlal Institute of Postgraguate Medical Education \\ and Research, Tamil Nadu, India
}

*Corresponding Author:

Email: aravindhankishore@gmail.com

\begin{abstract}
Turner syndrome is a pan-ethnic congential disorder caused by the partial or complete absence of one of the $\mathrm{X}$ chromosomes in females. Development of secondary sexual characteristics or menarche or spontaneous conception in Turner syndrome requires hormonal replacement therapy. Only a very few cases have been documented with spontaneous menarche with Turner syndrome. In this report, we are presenting a case of Turner syndrome, along with thyroid dysfunction who had spontaneous menarche.
\end{abstract}

Keywords: Spontaneous puberty, Spontaneous menarche, Turner syndrome.

Received: $19^{\text {th }}$ October, 2017

\section{Introduction}

Turner syndrome is a pan-ethnic disorder caused by the complete or partial absence of a second X-chromosome in females. The estimated incidence of Turner syndrome is between 1 in 2000 to 1 in 5000 live births. ${ }^{1,2}$ Almost, $50 \%$ of Turner syndrome cases are associated with a 45 , $\mathrm{X}$ karyotype, $25 \%$ with structural abnormalities of the second $X$ chromosome and $25 \%$ with 45 , $\mathrm{X} / 46$, XX mosaicism. Available scientific evidence show that ovarian dysgenesis is severe enough that only $10-20 \%$ patient have spontaneous puberty development (thelarche \& Pubarche $)^{3}$ and $2-5 \%$ have a spontaneous pregnancy. ${ }^{4}$ In this case report, we present a Turner syndrome case who attained spontaneous puberty without any medical intervention. To the best of our knowledge, this is the first case of Turner syndrome with spontaneous puberty reported in South-Indian population.

\section{Case Report}

A 16-year-old female was referred from Obstetrics and Gynecology Department to Cytogenetics division of the Anatomy Department of JIPMER for evaluation of Primary amenorrhea.

After obtaining written informed consent from the subject, she was evaluated clinically. Endocrinological work-up and ultrasound examination were done. Conventional karyotyping and Comet assay (single cell gel electrophoresis) was done using peripheral blood lymphocytes. Barr body examination from buccal smear was done.

On eliciting family history, her mother reported that she was born of a first-degree consanguineous marriage as one of the monozygotic twins (Fig. 1). She was born by vaginal delivery with birth weight of $2.2 \mathrm{~kg}$, and her size was small for gestational age (36 weeks). Also, mother said that the baby had widely spaced nipples, webbed neck and shield chest at birth. The other twin whose sex was unspecified was born with an anterior abdominal wall defect and lymphedema and died within seven days of birth (Fig. 1).

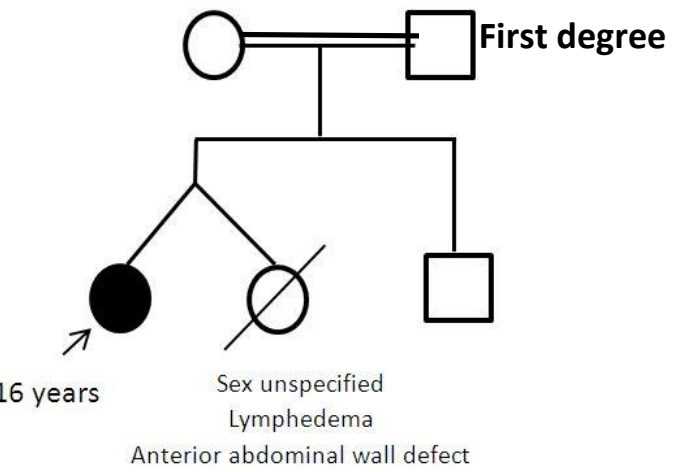

Fig. 1: Pedigree analysis of subject with Turner syndrome

On examination, the individual was shortstatured (height $133 \mathrm{~cm}$ ). She presented with typical Turner stigmata, which included webbed neck, cubitus valgus (Fig. 2), short fourth metacarpal and metatarsal (Fig. 3), low posterior hairline, widely spaced nipples, shield chest, absent pubic and axillary hair. We also observed mild enlargement of the thyroid gland. Laboratory 
investigations revealed hypothyroidism and increased anti-thyroid antibody levels suggestive of Hashimoto thyroiditis. Ultrasound imaging had

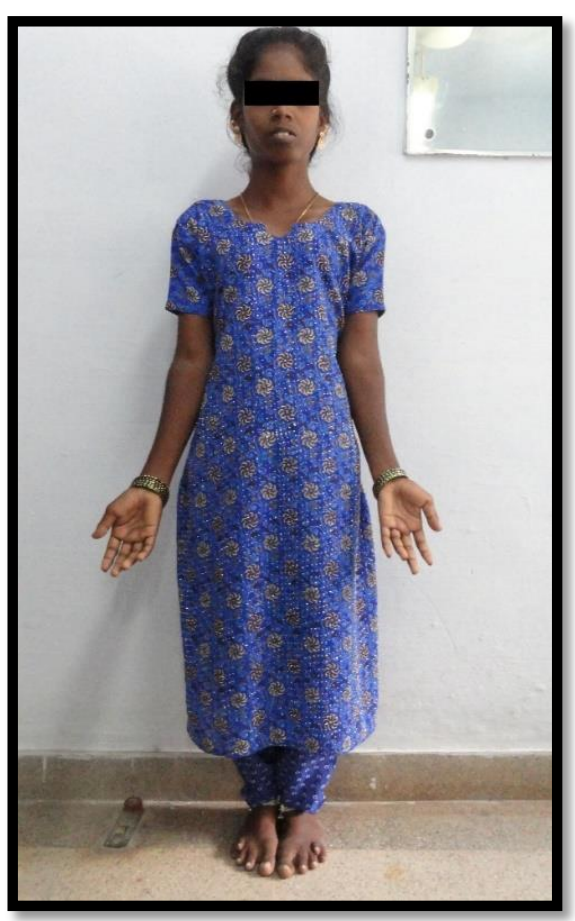

Figure 2a: Cubitus Valgus shown the presence of an infantile hypoplastic uterus, streak ovaries and no other abnormality were encountered.

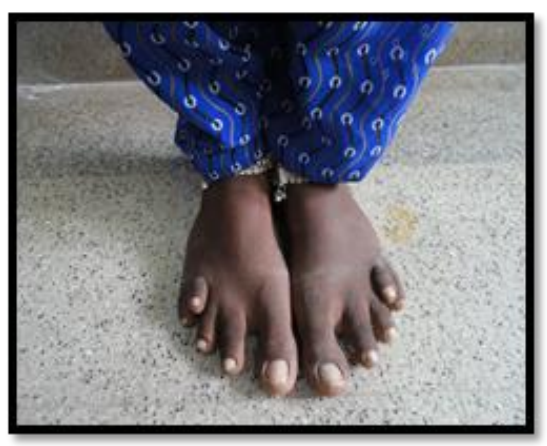

Figure 2b: Short $4^{\text {th }}$ metatarsal

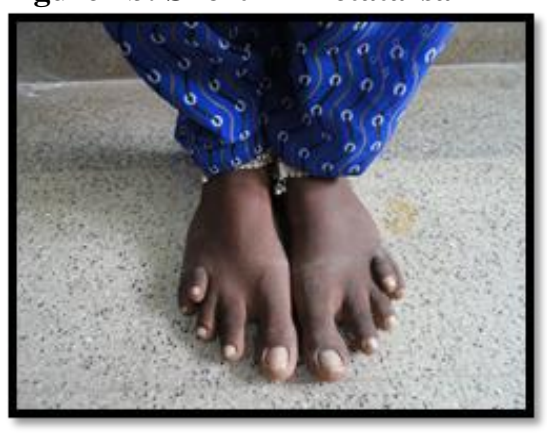

Figure 2c: Short $4^{\text {th }}$ Metacarpal

Chromosomal analysis: 100 metaphase spreads were captured and analysed using IKAROS metasystems. Conventional karyotyping with GTG banding revealed 45, X karyotype in most cells and 46, XX karyotype in few spreads (mosaic pattern).

Comet analysis: Comet parameters were analysed using Comet score software. Comet length, tail length \& head diameter showed elevated levels in subjects with Turner syndrome when compared to normal (Fig. 3, Table-1).

Table 1: Comparison of comet parameters between Turner karyotype and Normal karyotype

\begin{tabular}{|l|c|c|}
\hline Parameters & Turner karyotype & Normal karyotype \\
\hline Comet Length $(\mu \mathrm{m})$ & 90.60 & 52.30 \\
\hline Head Diameter $(\mu \mathrm{m})$ & 55.40 & 24.86 \\
\hline$\%$ DNA in Head & 85.50 & 71.45 \\
\hline Tail Length $(\mu \mathrm{m})$ & 35.20 & 25.46 \\
\hline$\%$ DNA in Tail & 10.25 & 3.74 \\
\hline
\end{tabular}

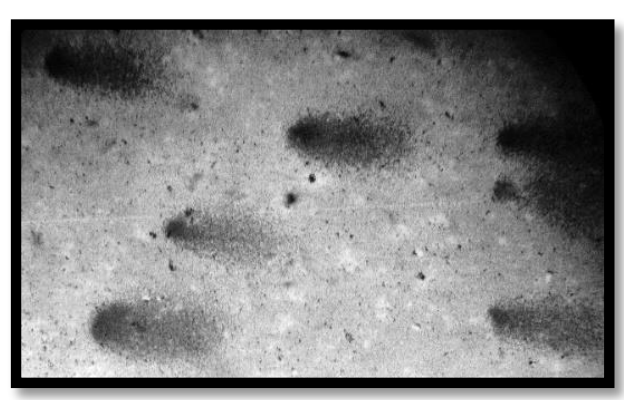

Fig. 3a: Turner syndrome (45, X/46, XX) Fig. 3: Comet Assay

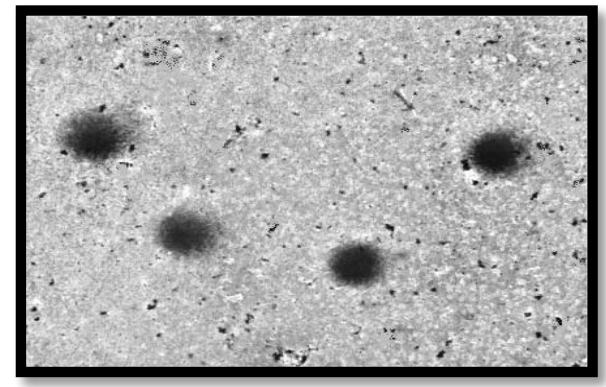

Fig. 3b: Normal female (46, XX) 
Mini-mental status examination was administered to the patient, which documented normal intelligent quotient. Hormonal assay had shown elevated levels of follicular stimulating hormone (FSH) (Table-2). Barr body examination was positive.

Table 2: Hormonal profile

\begin{tabular}{|l|c|c|}
\hline \multicolumn{1}{|c|}{ Hormones } & Values (normal range) & Observation \\
\hline FSH & $68.1 \mathrm{mIU} / \mathrm{mL}(1.5-33.4)$ & Increased \\
\hline LH & $17 \mathrm{mIU} / \mathrm{mL}(0.5-76.3)$ & Normal \\
\hline Estradiol & $45.8 \mathrm{pg} / \mathrm{mL}(20-570)$ & Normal \\
\hline Progesterone & $0.1 \mathrm{ng} / \mathrm{mL}(0.15-28.03)$ & Normal \\
\hline Prolactin & $4.9 \mathrm{ng} / \mathrm{mL}(2.8-29.2)$ & Normal \\
\hline
\end{tabular}

Follow-up: During follow up, the patient reported, having menstruation after three months, but she had irregular menstrual cycles. Since the patient had a mosaic pattern of karyotype, the patient was given hormonal therapy (Growth hormone) for increasing the height and estrogen for secondary sexual characters development for one year. Followed by which we observed an increase in the height of $4 \mathrm{~cm}(137 \mathrm{~cm})$ and Tanner stage 3 breast development.

\section{Discussion}

This case report describes a Turner syndrome female, who had spontaneous puberty. Ovarian failure is reported to be more common in Turner syndrome $^{5}$ which needs hormonal replacement therapy for achieving secondary sexual characteristics and for conception. There are only few evidences documenting the spontaneous menarche $^{3,6}$ and conception $^{3,7}$ in Turner syndrome. However, the mechanism is still unclear. We hypothesize, that spontaneous puberty, in this case, would have occurred due to the presence of normal $\mathrm{X}$ chromosome in many cell lines (mosaic pattern). This finding of our case report is in line with Pasquino et al. ${ }^{3}$ Treatment with Growth hormone supplementation was found to be effective by the evidence that the girl's height increased after one year by $4 \mathrm{~cm}^{8}$ Estrogen supplementation was given with the idea that the subject would have the development of secondary sexual characters and normal sexual life although she may not have normal reproductive life. Despite spontaneous puberty, conception was not spontaneous. Assisted reproduction was not possible, because of Hypoplastic ovaries. ${ }^{9}$

Different investigations, including comet assay and karyotyping, were beneficial for evaluating the Turner syndrome regarding DNA damage. Comet assay showed significantly increased levels of head diameter, tail length and comet length suggestive of DNA damage occurred during the fetal life leading to a chromosomal abnormality. Barr body examination was positive due to the presence of $45, \mathrm{X} / 46, \mathrm{XX}$ mosaic pattern observed in few cell lines. Although Barr body examination is not a specific test for diagnosis, it became a supportive evidence to indicate mosaic cell lines. Increased level of FSH hormones indicates the presence of streak ovaries. The delayed pubertal onset, in this case, could be attributed to the Turner syndrome per se and the additive effect of thyroid hormone dysfunction. ${ }^{10}$

Although a few cases have been documented about this, the exact mechanism of DNA damage is unclear. Consanguineous marriage may have led to the chromosomal abnormality in the fetuses. Death of the $2^{\text {nd }}$ twin baby born with lymphedema ${ }^{11}$ and the anterior abdominal wall defect would have been the reason that chromosomally abnormal babies do not survive \& the severity of chromosomal damage would have been high, and the fetus undergoes spontaneous abortion, or they die immediately after birth. ${ }^{12,13}$ To the best of our knowledge, this may be the first case to be reported in a south Indian population with a comet assay being done to assess the DNA damage level for Turner syndrome with spontaneous puberty to assess the DNA damage level. Molecular studies to find the aetiology of spontaneous puberty was not done, this being the limitation of this report.

\section{References}

1. Sybert VP, McCauley E. Turner's Syndrome. New England Journal of Medicine. 2004;351(12):1227-38.

2. Pinsker JE. Clinical review: Turner syndrome: updating the paradigm of clinical care. J Clin Endocrinol Metab. 2012;97(6):E994-1003.

3. Pasquino AM, Passeri F, Pucarelli I, Segni M, Municchi G. Spontaneous pubertal development in Turner's syndrome. Italian Study Group for Turner's Syndrome. J Clin Endocrinol Metab. 1997;82(6):1810-3.

4. Hovatta O. Pregnancies in women with Turner's syndrome. Annals of medicine. 1999;31(2):10610. 
5. Sybert VP, McCauley E. Turner's syndrome. The New England journal of medicine. 2004;351(12):1227-38.

6. Kocova M, Basheska N, Papazovska A, Jankova R, Toncheva D, Popovska S. Girls with Turner's syndrome with spontaneous menarche have an increased risk of endometrial carcinoma: a case report and review from the literature. Gynecologic oncology. 2005;96(3):840-5.

7. Tarani L, Lampariello S, Raguso G, Colloridi F, Pucarelli I, Pasquino AM, et al. Pregnancy in patients with Turner's syndrome: six new cases and review of literature. Gynecological endocrinology : the official journal of the International Society of Gynecological Endocrinology. 1998;12(2):83-7.

8. Massa G, Vanderschueren-Lodeweyckx M, Malvaux P. Linear growth in patients with Turner syndrome: Influence of spontaneous puberty and parental height. European Journal of Pediatrics. 1990;149(4):246-50.

9. Deligeoroglou E, Stergioti E, Dimopoulos KD, Karountzos V, Prapas Y. Pregnancy outcome after oocyte donation in patients with Turner's syndrome: Clinical experience and management. Journal of obstetrics and gynaecology : the journal of the Institute of Obstetrics and Gynaecology. 2016;36(4):504-7.

10. Livadas S, Xekouki P, Fouka F, KanakaGantenbein C, Kaloumenou I, Mavrou A, et al. Prevalence of Thyroid Dysfunction in Turner's Syndrome: A Long-Term Follow-Up Study and Brief Literature Review. Thyroid. 2005;15(9):1061-6.

11. Larralde M, Gardner SS, Torrado MV, Fernhoff PM, Santos Munoz AE, Spraker MK, et al. Lymphedema as a postulated cause of cutis verticis gyrata in Turner syndrome. Pediatric dermatology. 1998;15(1):18-22.

12. Gilbert B, Yardin C, Briault S, Belin V, Lienhardt A, Aubard Y, et al. Prenatal diagnosis of female monozygotic twins discordant for Turner syndrome: implications for prenatal genetic counselling. Prenatal diagnosis. 2002;22(8):697702.

13. Nance WE, Uchida I. Turner's Syndrome, Twinning, and an Unusual Variant of Glucose-6Phosphate Dehydrogenase. American Journal of Human Genetics. 1964;16(3):380-92. 